Int. J. Electrochem. Sci., 14 (2019) $5448-5461$

\title{
An Electrochemical Sensor Based on MB/Ag-ZnO/Graphene Modified Glassy Carbon Electrode for Determination of L- Tryptophan in Biofluid Samples
}

\author{
Yao Wang, Dan Li*, Junfeng Kang, Shiye Guan, Daoxin Wu \\ Hunan Provincial Engineering Research Center for Food Processing of Aquatic Biotic Resources, \\ School of Chemistry and Food Engineering, Changsha University of Science and Technology, \\ Changsha 410114, P. R. China \\ *E-mail: LD1004@126.com
}

doi: $10.20964 / 2019.06 .29$

Received: 1 February 2019 / Accepted: 23 March 2019 / Published: 10 May 2019

In this work, graphene (GR) and $\mathrm{Ag}-\mathrm{ZnO}$ nanocomposites were prepared and used together with methylene blue (MB) as electrode materials to modify a glassy carbon electrode (GCE). The electrochemical behavior of L-tryptophan (L-Trp) on the fabricated MB/Ag-ZnO/GR/GCE was investigated by cyclic voltammetry and differential pulse voltammetry. MB/Ag-ZnO/GR clearly enhanced the electrochemical oxidation of L-Trp. In a $0.1 \mathrm{~mol} / \mathrm{L}$ phosphate buffer solution at $\mathrm{pH} 4.0$, the peak current response at the modified electrode increased linearly with an increase in the L-Trp concentration from $2.0 \times 10^{-6}$ to $1.4 \times 10^{-4} \mathrm{~mol} / \mathrm{L}$, and the detection limit $(\mathrm{S} / \mathrm{N}=3)$ was $1.0 \times 10^{-6}$ $\mathrm{mol} / \mathrm{L}$. The electrode showed good reproducibility, stability, and selectivity. The sensor was used for the determination of L-Trp in biofluid samples (pig serum and pig urine), and the recovery rate ranged from $97.1 \%$ to $104.2 \%$. The fabricated electrode was proposed for the electrochemical analysis of LTrp, indicating the potential for practical applications in the biological field.

Keywords: Graphene, Ag-ZnO nanocomposites, L-Tryptophan, Methylene blue

\section{FULL TEXT}

(C) 2019 The Authors. Published by ESG (www.electrochemsci.org). This article is an open access article distributed under the terms and conditions of the Creative Commons Attribution license (http://creativecommons.org/licenses/by/4.0/). 